\title{
EXPERIENTIAL EDUCATION AND LANGUAGE IMPROVEMENT THROUGH P2P INTERNATIONAL PROJECTS
}

\author{
Paul Gordon Dickinson ${ }^{\mathrm{i}}$ \\ Senior Lecturer, \\ PhD International Business, Cert (TEFL), \\ Department of Business and Management, \\ Laurea University Finland, \\ Hyvinkaa, Finland
}

\begin{abstract}
:
In order to meet the needs of employers and to make students more employable Laurea University, Finland has developed an "experiential" educational model through projectbased learning in English based around real business projects linking theory studied. The programme is a bachelors degree conducted with international exchange students from many different countries (including Turkey, Germany, Romania, Spain, China, Holland, Mexico, Japan, and Italy) within project teams. English is a second language to these students, but it is not known as to how and if their language develops during the programme. The study considers the "experiential" nature of both the programme and the language from a literature perspective then focusing particularly on the learning of English by the students without any formal teaching classes. The students participated within projects for one semester (via an exchange programme) during an academic period from August 2018 to May 2020. There is a quantitative empirical approach (using a written questionnaire) which was qualitative in nature (including open questions) which related to the assessment of the English language learning experience of 29 international exchange students. Their feedback via answers to written questions forms the basis of the study. Findings reveal that such an approach to language learning can be successful and was positive in the sense of flexibility, relevance and enjoyability as well as the easy access and help of technology. The students generally felt their language level had improved through informal discussions and by use of a language app connected to the project work. Also, some students felt that the "learning by doing" (through the projects) improved their language authenticity and application. However, some students felt their language learning would have further increased by the use of a "weekly relevant noun/adjective list" during the project meetings. The research overall shows that some language improvement can be achieved informally within an "experiential" educational model through project-based learning. Additionally, that can be within one semester and by students from different countries with different educational systems.
\end{abstract}

i Correspondence: email paul.dickinson@laurea.fi 
Keywords: language learning, experiential, technology, education, projects

\section{Introduction}

In today's connected and demanding world, the pressure of immediate employment possibilities for graduates is a constant desire and universities have to respond quickly and accurately to the needs of the learning and business communities. Since 2008 Laurea University (Laurea) has changed its approach from traditional teaching methods to student centred ones, within its learning processes. The educational framework for learning at Laurea is called 'Learning by Development' (LbD), which is the systematic development of an interaction between training and the reality of working life. This way of learning fits into the overall concept of alternative education. Within that overall framework Laurea introduced in 2008 a bachelors business and project management degree programme for both domestic and international exchange students. This programme is called " $\mathrm{P} 2 \mathrm{P}$ " and can perhaps be classified within the type referred to as an "experiential" form of learning, and that is assessed within the paper by academic review." Experiential" learning is a method where teachers and students interact through experience and focused reflection to increase knowledge and develop skills and the learning is by doing, experience, or discovery (Dickinson, 2017). Language learning can also be of an "experiential" nature and the core of this paper explores this. Whether and if so to what level this has been the case within the P2P programme with the learning of English, within the international projects and how successful that has been. The objective of this paper is to consider and assess "experiential" learning of English as a second language from a theoretical and practical perspective through the "P2P" "experiential" form of education. In particular to consider how that takes place, what kind of support international exchange students have (including the use of technology)and some of the positive and negative outcomes of learning a language this way. The P2P model is described and the project process the international students are involved in as well as to how well the model fits as a form of "experiential" learning. The P2P model is also commented on at various stages in the paper within the language learning process of the international exchange students to show the connection between the projects and the learning process. There is also an academic consideration of what experiential language learning can consist of and a section on technology as a language support for students. Finally, the theoretical aspects are followed by qualitative empirical research of international exchange students from various countries as to how and what they achieved in their learning and/or improving of their English as a foreign language during one semester within the P2P project system. Recommendations and a conclusion as to the overall view on this type of language learning completes the paper.

\subsection{The P2P Model}

The P2P degree programme model is totally in English for the international business projects, which are strongly connected to the reality of work. The students learning is directly linked to the projects from the start of their studies. A clear motivational factor 
for the students is the project briefing at the beginning of the project and the assignment is given to them by the company representative, not by the teacher (see Figure 1 below). In this unique programme there are no lectures or exams, the students work in teams to solve business problems. Lecturers are regarded as "elder colleagues" whose role is to supervise as a mentors the "younger colleagues" in their projects and there are normally one or two lecturers to a project which will have 5/6 students from different countries. The objective is to allow the students to become more independent during their studies and to raise future professionals that will not hesitate to start identifying and solving a business problem. The themes and contents of the projects vary, but are generally related to ;business operations, marketing, management, communication, or finance and can be connected to any country as a target market. Very common themes are export / import, creating marketing plans to a new market, finding new target groups or possibilities for using social media in business operations. Projects are implemented with very different organizations; small and large businesses, associations or even governmental bodies, but share one similar characteristic, they are all development projects aimed at solving a problem that is important for the organization, which the organization itself has neither time nor knowledge to solve. The international students are placed into two or three of these international projects for a complete semester (approximately four months )and from the word go the communication and group interaction is in English. There is a weekly hourly meeting with the lecturers to discuss the project progress and also the student team meet at a regular weekly time to work together. The project normally lasts one semester (approximately four months). At all stages of the project process the communication is in English which is a second language to the team members and although a minimum level of understanding in English is required for participation, the language level generally varies a little from student to student within each project team.

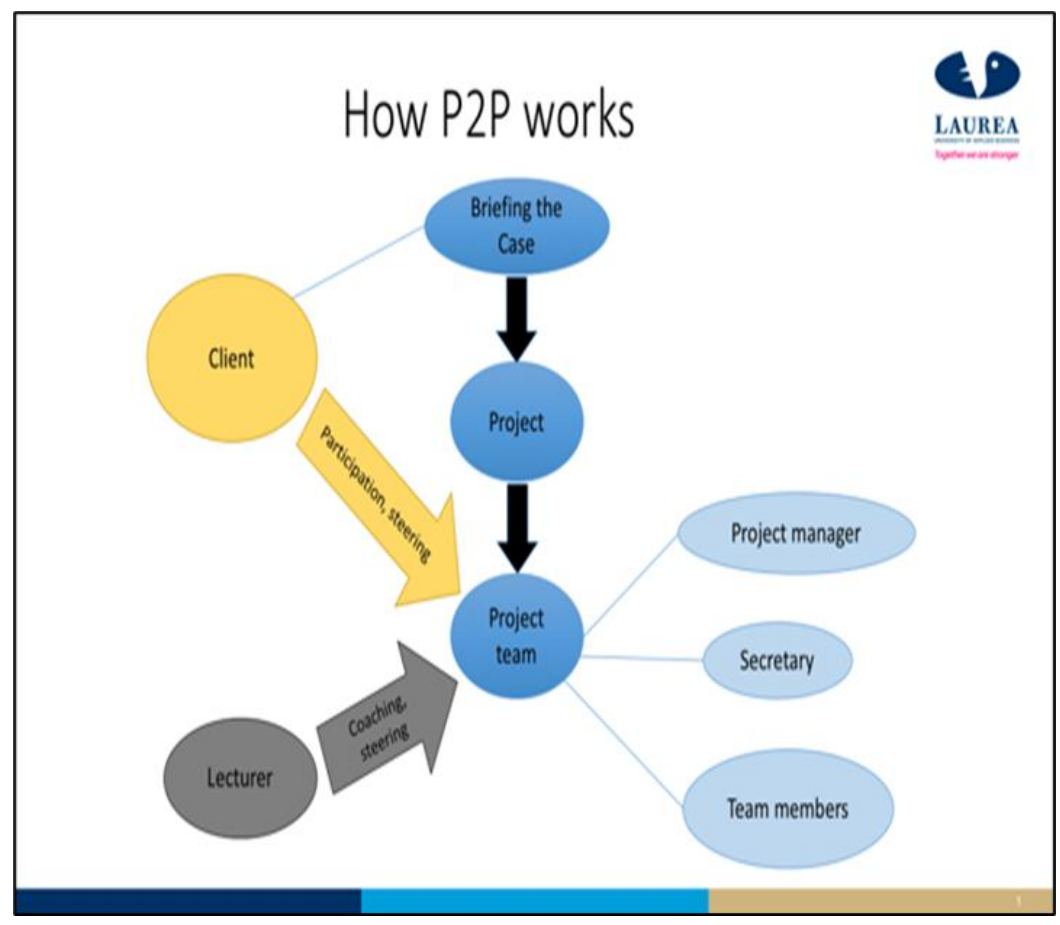

Figure 1: How P2P works 
In Figure 2 (below) the P2P process, (starting with the assignment and ending with the evaluation) shows simply the various aspects of the process and when they take place. The international projects are free of charge to the businesses/organisations (for the first one)and often there is a follow up project. Many of the representatives participate actively in the process, and thus give their time and expertise. This participation both increases the motivation of the students, as they see that the project and its success is important to the client and helps the students to create networks and relationships to promote their future careers. Sometimes, the project assignment, given by the business/organisation at the beginning of the project is quite vague and, in some cases, they do not know, what exactly they want. A typical case is a very abstract problem such as, "We need a Marketing Plan". In these cases when students (and teachers) start asking questions, it becomes clear quite soon, that the business or organisation itself does not have a defined idea, what should be included. Further discussions then take place between all parties to get a specific achievable objective. At this point a project manager and secretary are appointed from the team to lead and record meetings respectively. After the approval of a project plan by the lecturers and the signing of a legal agreement between the clients and the team, the students draw up a "mind map "that clearly presents the theoretical parts included in the project. In order to do this, they have to familiarize themselves with the theme in question and read books, academic articles and other research materials. A well built mind map that is approved by the supervising teacher forms a basis at least for the theoretical part of the project, but quite often also for the table of contents for the final project report. The main challenge for the students lies in combining the theoretical and practical parts of the project as all the theory has to be clearly linked to the project and all the sources need to be clearly marked.

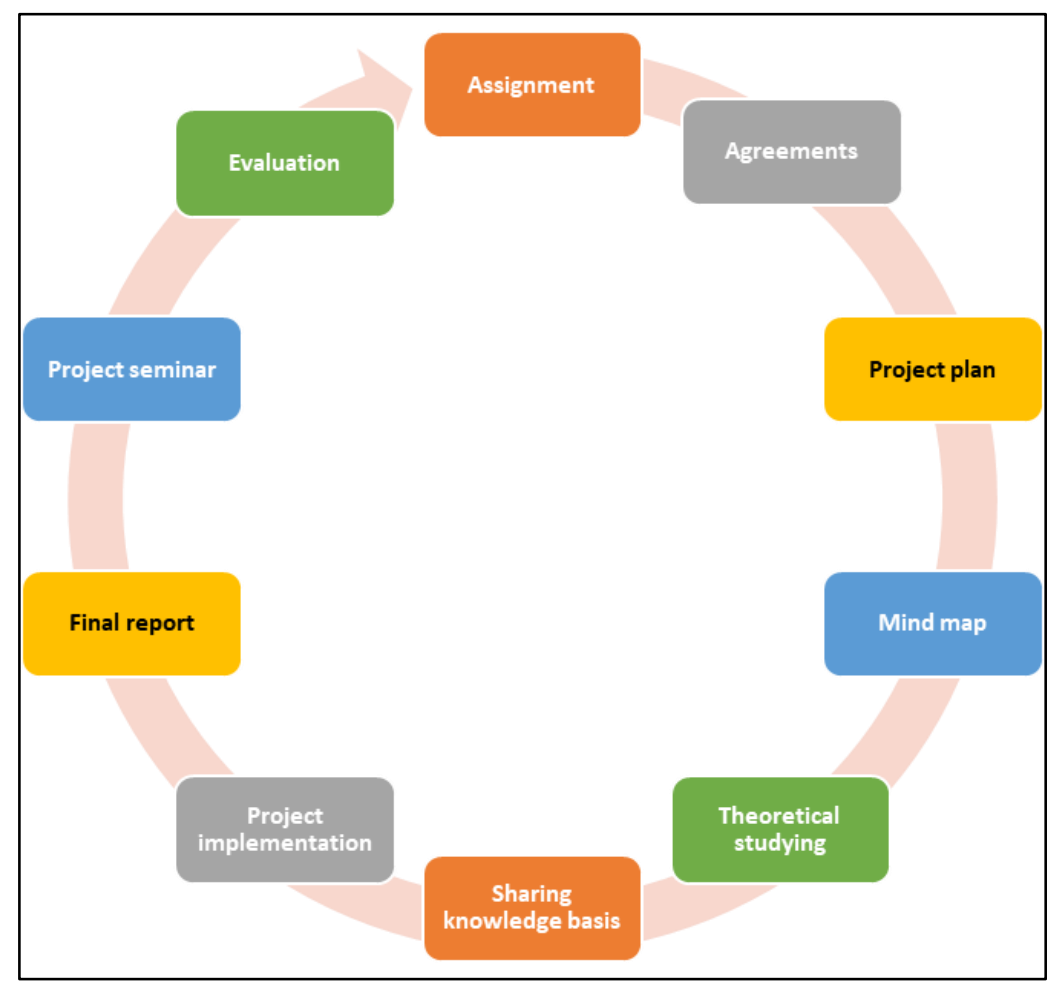

Figure 2: The P2P process 
The final result of a project is a large report consisting of theoretical and practical part of the project, as well as conclusions and further recommendations. The project results are presented to the client at the end of the project either at P2P office, in the company or by using technology such as Skype/Zoom. At the end of each project an evaluation discussion is held, and both the process and results are evaluated. Within the evaluation special attention is paid on co-operation within the team and client feedback as well as the writing and linking of the theory.

\section{Literature Review}

\subsection{Experiential Learning Theory}

Kolb (1984) is often regarded as a consummate academic author in relation to experiential learning and added to the earlier work of John Dewey and Kurt Levin, Kolb believed that learning is the process whereby knowledge is created through the transformation of experience. He indicates that there are four "key" aspects to the idea of "experiential" learning; firstly concrete experience where the learner actively experiences an activity (doing) such as field work, secondly reflective observation when the learner consciously looks back (reflecting) on that experience, thirdly abstract conceptualization which is where the learner attempts to conceptualize a theory or model (thinking) of what is observed and fourthly active experimentation which is where the learner is trying to plan how to test a theory or plan (planning) for a coming experience. Other academics give further informative comment that "experiential" learning is any learning that supports students in applying their knowledge and conceptual understanding to real problems or situations where the mentor/instructor directs and facilitates learning. "Experiential" learning is an alternative educational approach which aims at integrating theoretical and practical elements of learning for a whole-person approach, emphasising the significance of experience for learning. It can have various settings of informal learning, such as internships in business and service organisations, work and study assignments, clinical experience, as well as international student exchange programmes. However, the principles and practices can be used both in formal learning (institutional) contexts and in informal learning. "Experiential" learning techniques include a rich variety of interactive practices whereby the participants have opportunities to learn from their own and each other's experiences, being actively and personally engaged in the process and includes personal journals, diaries, reflective personal essays and games and simulations, personal stories, story-telling, discussions with others and reflection in cooperative groups. All of these contain a common element of learning from immediate experience by engaging the learners in the process as whole persons, both intellectually and emotionally. "Experiential" learning involves observing the event or situation and doing something meaningful with it through active participation and it emphasizes learning in which the learner is directly in touch with the event or situation being studied, rather than just watching it or reading, hearing or thinking about it.

Moore (2010) provides an interesting overview of "experiential" education including; internships, undergraduate research, and studying abroad and believes that 
"experiential" learning can have a transformative effect on students, but he says those effects depend on careful planning and execution, and avoiding the tendency to fall back on the adage that every experience is educational, and on pushing students and staff to think rigorously and extensively about the intersections between theory and practice. When considering those elements with the P2P programme and process it is quite clear that those four stages are present (doing, reflecting, thinking and planning) and the international students are applying their knowledge and conceptual understanding to real problems provided for by actual companies or entrepreneurs within a business environment through the format of a project supported and directed by a mentor,(one or two lecturers). Also, the activity as a whole for the international students is part of an international exchange programme which has been identified in itself as "experiential" particularly if there is careful planning and implementation and a strong connection between theory and practice as specified (loc cit). Having indicated that the P2P model is of an "experiential" type of educational model, what of the learning of the English language used during the project process?

\subsection{Experiential Language Learning}

The vast majority of teaching and training in language education and work continues to be conventional, narrow and highly prescribed not "experiential". This is the situation in spite of language use being social, requiring learners to adapt not only to a new code for expressing themselves, but also to become aware of new and different cultural expectations, social norms, and practices (Mollei, 2012). However, although this is true with regard to the majority of teaching there is perhaps a " wind of change" coming over education with "experiential" approaches gaining more support as they give students a more practical connection to the work place and a more self-reliant outlook which can often make them more employable.

Supporting this perspective in recent years foreign language has emphasized more the significance of the students' own contributions to their language learning through initiative-taking and active involvement. Students need to be the leader of their learning in order to enhance their autonomy as students and language users. This shift in the research has brought an increased interest in the idea of the students themselves as learners in general and as language learners in particular. An interesting recent study took place in Iran (Shariffi,2017) which involved this shift where data for a study was collected from a total of 30 learners of English as a foreign language who studied English at an elementary level in two different classes of the same language institute in Rafsanjan. They were of the same level and age and from the same institute. In one group the teacher asked students to do what she wanted to teach them in the class, to do it practically and in the other group she did not she just taught the sentences with the meaning and not by doing it practically. The first class can be described as of an "experiential" nature and the second class of a typical controlled type and what is an interesting finding was that in the post-testing the "experiential" group outperformed the traditional group in terms of language skills improvement. The author also indicates that the evidence found that there was a positive influence and impact from the "experiential" approach particularly that 
the most important outcome from the testing of the two groups was the fact that the students needed adequate motivation for learning and although there was an appreciation of when learning is fun it was not enough. Furthermore, an awareness of the real-world requirements and employability was found with all the students and that the overall research could be generalized to the Iranian population as a whole. Although there are differences from the P2P international projects (different nationalities, ages, and to a limited extent levels of language) within the "experiential" teaching system the "doing" the "enjoyment" and "relevance" stand out as common features enabling the learning of the language.

Significantly in the context of this paper there is some academic weight given to the argument that so called "out-of-class" projects which are incorporated into language learning can improve a learners' language by activating it in an authentic setting as well as increasing their repertoires and communicative ability. (Choi and Nunan (2018, p51), comment more specifically that "it is important to provide language learners with opportunities to communicate outside a classroom." Furthermore, when commenting on "experiential" education and language learning states ...project-based learning is full of rich learning opportunities. Well-designed projects help learners see language learning and activation as processes, and that it is the learners themselves who need to take responsibility for their own learning (loc cit).

Although the P2P projects are not incorporated specifically into a language programme and the weekly project meetings with lecturers take place in an open classroom, they do provide an authentic setting for such improvement. Additionally, there are regular client meetings which can be at the clients' premises which aid such authenticity. Choi and Nunan (loc cit) go on to further comment on the fact that a "classroom" only language environment is inadequate for achieving high levels of proficiency in a second language. This is corroborated by Pfenningger and Singleton, 2017 p.180, who considered "out of class-room experiences" (such as studying abroad) and concluded that they were very connected to a foreign language learners' proficiency and verbal performance. Another important aspect to the language learning from being within an authentic worldly situation is that students learn the rules of the conversational game from a cultural communication perspective which gives their learning and added dimension. An example of this could be so called "high and low context" communication patterns referred to by Edward Hall and commented on by (Tomalin, 2013). Within the P2P project a client could be French or Finnish and the cultural impact on communication at client meetings with student teams would be quite different and has been in such situations. Finnish communication is of the "low context" style and as such is very direct and little small talk is needed whereas the French communication style (although some variation between north and south) is "high context" requiring polite, indirect style placing points made in context with the reasoning and with small talk. The student learns the reality of the language and how it is used in this situation in an authentic pressurised situation.

The communication situation can also be affected by external environmental factors such as whether the conversation is on the phone, face to face or using internet 
appliances (WhatsApp/Skype/Zoom) which have an effect on their communication effectiveness as commented on by (Choi and Nuun, p53). The students have to work things out quickly with their language use because in an authentic "out-of -classroom" situation there are emotional factors of anxiety, of using the target language in a real situation with the pressure to perform. It is fair to say the roles within the P2P international projects provide such cultural knowledge and power relationships (lecturer, project manager, secretary) the rules of the game for the communication with the client (who is generally a different nationality) and in a real business setting can provide an anxiety and provides a real pressure to perform. The communication is either face to face or via WhatsApp/Skype/Zoom (the latter being much more prevalent during the Covid pandemic). Certainly, tone of voice and pronounciation of the language become more important when it's not face to face or there is no computer screen, when the reality of the absence of body language to support real meaning of the communication, can pressurise the student even more.

On further consideration of the overall "experiential" language idea some academics believe students need to be facilitated to develop a basic reflective orientation, by working on their experiences, beliefs and assumptions of language and learning. This is indicated by Kohonen (1996), who comments on the idea of "experiential" language learning involving four "key" points. Firstly, an abundant input in target language, secondly learner reflection on language, thirdly comprehensive output with productive use of language in interactive communication, and fourthly corrective feedback by teachers and/or peers. Looking at these "key" points within the P2P international project programme it's fair to say, firstly the language of English is used extensively in both the project meetings with the lecturer (one hour a week per project) and during the student team weekly meetings (eight hours a week per project). Additionally, the international students socialize (in some cases live together in shared accommodation)and have interactive communication together often having reflective discussion with each other about their projects. Also, the language is productively used during the meetings in an interactive way, as students are asked directly by the lecturer mentors questions in English during the project process and connected to business theory matters.

Corrective feedback by lecturers may occur during the weekly hourly project meetings with the teams for example if there is a mistake as to the pronunciation and/or use of a common business meeting noun or adjective(for example the word "agenda" is sometimes pronounced incorrectly with a hard " $\mathrm{g}$ "). Professional language which is understandable is regarded as the most important aspect of the communication and if an important English language word is mispronounced or not used correctly it will be commented on. In a similar way very good use of language within the meeting may be given complementary comments. Also, written English used in memorandums and in theory parts is given feedback and commented on with constructive criticism where necessary. It's also fair to say that the international student teams receive peer feedback, that is from each other in a similar way.

Consequently, the definition given by Korhonen (loq cit) in relation to "experiential" learning of language fits with that learnt within the P2P project system by 
the international exchange students. However, with the second and third points improvements could be made. Certainly, being reflective on your work yourself is part of the P2P process and self-evaluation is encouraged in an ongoing way, as well as being part of the final evaluation process but reflection on language progress could be more directly encouraged. The fourth point within the definition of corrective feedback by teachers/peers is perhaps also in need of more rigorous systematic structuring within the system. It is important that people's perceptions and feelings of competence are enhanced, as their motivation will be increased because language learners need positive experiences of what and how much they can do in a communication sense, competence develops through confidence (loq cit). This can be encouraged and developed by teaching that supports the learner's self-assessment of his or her own learning, both alone and with peers in cooperative learning groups and of course non-traditional forms of teaching such as mentoring within the $\mathrm{P} 2 \mathrm{P}$ project system try to do this.

\section{Technology's Role}

As indicated by Dogoriti and Pange (2014), due to the integration of networked technology and it's use within higher education new learning styles have evolved and the tools for these new practices are changing. In particular asynchronous communication (e.g. e-mail, blogs, discussion boards) and synchronous communication (e.g. instant messenger) has transformed learning with their emphasis on collaboration and communication. Research also indicates that computer technology can help support learning and is especially useful in developing the higher-order skills of critical thinking, analysis, and scientific inquiry "by engaging students in authentic, complex tasks within collaborative learning contexts" (Roschelle, 2000). Both in the P2P programme itself as well as with the use and learning of the English language within the programme, learning technology plays an important supporting role. Within the P2P process (particularly if the client companies or located abroad)at the start of the project there may be an on-line (via computer technology) discussion with all students, teachers and company representatives when the company's' objective for the project is stated and discussed. During the projects the students use the internet for research tasks as well as software to put tasks in diagram or table form and the use of the email, of course allows cheap, quick contact for everybody. Students are also encouraged (by the project teachers) to use language apps to support their English learning (such as Duolingo) as well as online language translators and additionally the students often (encouraged by the project teachers) form a "social media communication" group usually WhatsApp/Facebook which they use to communicate in English about the project. At the end of the project technology again maybe used to make a presentation on-line including discussion, question and answers and feed- back relating to the project in English. 


\section{Research Methodology (Validity and Reliability)}

The methodology used was a written questionnaire sent to participating international students in the P2P programme during the academic years 2018 and 2020,which was of a mixed nature. Quantitative methods and data usually consist of closed questions requiring a yes or no answer as in a questionnaire whereas qualitative methods and data has open responses as indicated by (Cresswell, 2014, p43). It was of a mixed nature in the sense that there were some questions which were seeking a response in terms of ticking of boxes with a yes or no answer and some questions requiring a ticking of an improvement quite a lot, a lot, or hardly at all (an abbreviation of the Likert scale) and of a quantitative style. Others were open ended questions requiring opinion as to how and why and of a qualitative style. Research methodology is judged for rigour and strength based on validity, and reliability of the research (Morris and Burkett, 2011). Firstly, considering the reliability aspect it measures consistency, precision, repeatability, and the trustworthiness of research and it should indicate the extent to which it is without bias and error free ensuring consistent measurement across time (Chakrabarty, 2013). In this particular research the same questionnaire was sent to the different respondents over a time period of four semesters providing consistency and data was collected via email response to the questionnaire which was sent to individual email addresses. Additionally, the questionnaires were sent shortly after the project evaluations at the end of each semester which provided the respondents with no bias issues and allowed them to be honest with their answers and opinions. In this particular situation, the students were known to the researcher and the researcher was involved with the programme and although the respondents' answers were not anonymous, personal distance was provided through use of the research method (written questionnaire)and the respondents would not be seeing the researcher again consequently the trustworthiness of the research was not an issue.

In quantitative research, validity is the extent to which any measuring instrument measures what it is intended to measure (Thatcher, 2010) and it has two essential aspects internal (which deals with credibility) and external (transferability). With internal validity it means how legitimate are the results in the sense of how the data was recorded and the groups for the research selected (Willis, 2013). In this particular research the group selection covered all international students on the programme over an academic year(regardless of level, nationality or interest in the research) and the data was received in written form, collected and the answers recorded from that direct written information given to specific questions. The researcher avoided leading open questions in the questionnaire and trying to manipulate to get a certain type of answer, this ensured validity in the answers from the respondents. With regard to external validity and transferability it is quite a unique programme in the sense of it being of an "experiential" nature (as discussed in the paper earlier). However, the objective of the study relates to the "experiential" learning of a foreign language (in this case English) and the study could be replicated in other institutions on other programmes where there was no formal teaching of a language although the programme itself was in that language. Particularly 
as to how the students learnt/improved their language skills (eg through technology) and how motivated and enjoyable they found it and as to whether their language skills had improved. The study is consequently transferable to the learning of foreign languages (as a second language) generally not just English provided the programme offered is in that language and there are no native speakers who are respondents in the study.

\section{Empirical Results and Findings}

The number of questionnaires sent (by email) during the four consecutive semesters was 45 and there were 29 replies received and assessed providing a response rate of just over $64 \%$. According to (Keengwe, 2015) a 50\% response rate is rated as adequate, a $60 \%$ good and above $70 \%$ rated at very good, consequently the response rate here was good.

Of those 29 respondents asked as to whether their level of English had improved a lot/quite a lot or hardly at all $26(89 \%)$ indicated that it had improved(a lot/quite a lot) and when also asked to explain in an open question why or why not, of the three who had said hardly at all, two said because they were already at a high level prior to the exchange and one said that she was at a high level and did not receive enough detailed feedback. Significantly, of the 26 who said yes to an improvement when answering why, 16 indicated that it was due to either something real or connected to the project or because of, learning by doing. This was a very positive finding showing a $61 \%$ of those respondents indicating a language improvement identifying a connection to the project work as a reason. However, the fact that they are self-assessing that improvement is a limiting factor as it is clearly subjective. Some students identified what had improved (eg speaking / vocabulary) whereas some didn't, and in relation to that aspect the most significant identification was that seven $(24 \%)$ of the respondents indicated that their speaking had improved. Another important finding was that $19(65 \%)$ of the respondents answered that they were more motivated, and found it more enjoyable and relevant to learn a language this way.

Of the 29 respondents when asked if they used technology to support their learning (e.g language / translator app / on line dictionary) 22 said yes (75\%) and when further asked about other methods 22 (75\%) said that conversation between other exchange students had helped their language. Facebook and What's App were mentioned by the students as the most effective technical communication method to chat and improve their language 10 respondents (34\%).

There was a further question asked about a future suggestion in relation to their language learning and usefulness namely a written short list of relevant nouns/adjectives/phrases to be given before different stages of the projects and to be practiced during the teachers' weekly project meetings. The number of respondents which agreed and felt that would be at least useful was 16 (55\%). This indicates that some further specific direction and guidance was required in relation to the language learning by the majority of the student respondents. Consequently, the findings show the significance to the students of two clear aspects, enjoyment, and authenticity of the project work, within the language learning, which resulted in an overall improvement. 


\section{Recommendations}

Enjoying a way of learning a language and socializing together (using that language for communication) can be taken as positive ways of learning.This together with an everincreasing use of technology readily available to support that learning, seems to be the way forward for educational organizations and other language providers. Of course, as mentioned this requires self-discipline and motivation from the student themselves in their learning, which should it is suggested being pointed out clearly to students about to engage in such "experiential" learning. However perhaps there is always a need for some kind of direction and support within that learning, by teachers who are part of such "experiential" learning systems. It would also support the fourth specific requirement commented for "experiential" language learning that of "corrective feedback" by teachers, referred to by Kohonen (loq cit). Although this may further enhance their language development it is important that it should not take anything away from their learning enjoyment, or from the relevance of actual authentic language and how it's used in reality, through business project participation. These recommendations appear to be very important aspects particularly in relation to affecting student motivation according to the findings of this paper.

\section{Conclusion}

Language learning within an "experiential" system itself(in this case English as a second language through projects) can be successful, certainly from the perspective of the students doing the learning and trying to improve their language level. As indicated in the literature and referred to in this paper the "out-of-classroom experience" of language through the authentic nature of business projects, allows a student to increase vocabulary and engage in the cultural context reality of the language, but the responsibility of such learning is on the student themselves. Additionally, the empirical results of this paper show that one of the most successful ways students found for improving their English language was through chatting together socially and learning from each other. This was helped by the fact that they were accommodated together as exchange students and tended to socialize within small groups with English as the common language for social discussion. With regard to whether the language level had improved the overwhelming majority of the students answered that it had. The authenticity of language through the the actual "learning by doing" within the projects is an important point referred to by academics within the literature review (Choi and Nunan, Pfenningg and Singleton) as well as being mentioned within the empirical results by students. It is through this that "experiential" education via projects can particularly help "experiential" language improvement. Although what must be taken into account is that there was no objective independent assessment of that improvement and it was a single study within one institution albeit over four semesters with many different nationalities. It is perhaps fair to conclude that this study brings some useful information and guidance to the learning of foreign languages generally and the reality of "experiential" language learning 
through a projects-based education. Namely authenticity and enjoyment are important to students and technology use can be very beneficial in such circumstances. Additionally, perhaps further general conclusions from those points can also be made. That generally enjoyment in the learning of a language is a significant factor to be taken into account in motivating learners as well as the authenticity of using that language in real world situations. Consequently, the findings of this research, perhaps has wider implications than initially appears, particularly for higher educational institutions embarking on such alternative education approaches.

\section{Conflict of Interest Statement}

The authors declare no conflicts of interests.

\section{About the Author}

Paul Dickinson has been a Senior Lecturer for over 10 years at Laurea University, in the department of Business and Management Hyvinkaa Finland. He has worked on over 120 international projects during this time, and also been an exchange student tutor and English language teacher. He has also conducted culture and business lectures and is particularly interested in SME's, cross cultural communication and project management.

\section{References}

Chakrabarty, S. (2013). Best Split-Half and Maximum Reliability. Journal of Research and Method in Education, 3(1)p1-8.

Choi J., Nunan, D. (2018). Language Learning and Activation In and Beyond the Classroom. Australian Journal of Applied Linguistics, 1 (2), 49-63 (2018). https://journals.castledown-publishers.com/ajal/

Cresswell, J. (2014). Research design qualitative, quantitative and mixed method approaches 2014. Sage pub.

Dickinson P. G. (2017). The P2P educational model providing innovative learning by linking technology business and research. Universal Journal of Educational Research 5(10) 2017.

Dogoriti E., Pange J., Anderson S. (2014). The use of social networking and learning management systems in English language teaching in higher education. CampusWide information systems, vol 31 issue 4 pp 254-263. MCB Emerald pub.

Keengwe, J. (2015). Handbook of Research on Educational Technology Integration and Active Learning p350 IGI Global pub.

Kohonen V. (1996). Experiential language learning :second language learning as cooperative learner education.

Kolb, D. A. (1984). Experiential learning: Experience as the source of learning and development. FT press.

Mollei, F., Rhanama, H. (2012). Experiential education contributing to language learning. International journal of humanities and social science vol 2 no 21. 
Moore, D. T. (2010). Forms and issues in experiential learning. In D. M. Qualters (Ed.) New Directions for Teaching and Learning (pp. 3-13). New York City, NY: Wiley. Morris, E., Burkett, K. (2011). Mixed Methodologies: A New Research Paradigm or Enhanced Quantitative Paradigm, Online Journal of Cultural Competence in Nursing Healthcare, 1(1), p27-36.

Pfenningger, S., \& Singleton, D. (2017). Beyond age effects in instructional L2 learning. Bristol UK: Multilingual Matters.

Roschelle, J, Pea, R, Hoadley C, Gordon D, Means, B. (2000). Changing how and what children learn in school with computer-based technology. Children and computer technology, 10(2), p76.

Sharifi N, Shariati, M. (2017). Using Experiential Learning to Enhance Students' Foreign Language Proficiency. Translation journal July 2017. www.translationjournal.net.

Thatcher, R. (2010) Validity and Reliability of Quantitative Electroencephalography. Journal of Neurotherapy, 14, p122-152.

Tomalin, B. (2013). Cross cultural communication-theory and practice .Palgrave Publishing.

Willis, J. (2007). Foundations of Qualitative Research: Interpretive and Critical Approaches. Sage Publications. 
Creative Commons licensing terms

Authors will retain the copyright of their published articles agreeing that a Creative Commons Attribution 4.0 International License (CC BY 4.0) terms will be applied to their work. Under the terms of this license, no permission is required from the author(s) or publisher for members of the community to copy, distribute, transmit or adapt the article content, providing a proper, prominent and unambiguous attribution to the authors in a manner that makes clear that the materials are being reused under permission of a Creative Commons License. Views, opinions and conclusions expressed in this research article are views, opinions and conclusions of the author(s). Open Access Publishing Group and European Journal of Alternative Education Studies shall not be responsible or answerable for any loss, damage or liability caused in relation to/arising out of conflict of interests, copyright violations and inappropriate or inaccurate use of any kind content related or integrated on the research work. All the published works are meeting the Open Access Publishing requirements and can be freely accessed, shared, modified, distributed and used in educational, commercial and non-commercial purposes under a Creative Commons Attribution 4.0 International License (CC BY 4.0). 